\title{
Autopercepção da perda de dentes em idosos*
}

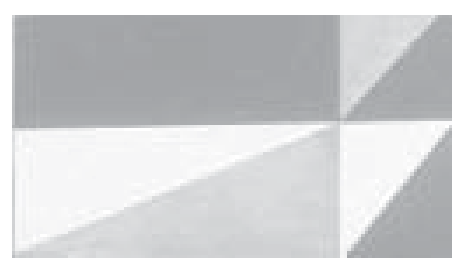

\author{
Beatriz Unfer ${ }^{1}$ \\ Kátia Braun² \\ Caroline Pafiadache da Silva ${ }^{3}$ \\ Léo Dias Pereira Filho ${ }^{4}$
}

UNFER, B. ET AL. Self-perception of the loss of teeth among the elderly. Interface - Comunic., Saúde, Educ., v.10, n.19, p.217-26, jan/jun 2006.

The objective of this work was to analyze the perceptions of a group of elderly people regarding loss of teeth. A qualitative study was conducted that used the Discourse of the Collective Subject as a methodological technique for ordering the data. The analysis of the interviews and the construction of the Discourse of the Collective Subject disclosed information on the thoughts and values associated with the loss of teeth within this group. The main results suggest that the lack of teeth caused functional and psychological problems, but that these appeared to be offset by solving the aesthetic problem. The justifications disclosed by the collective subject for edentulism predominantly reflect the healthcare model, which focuses on surgical, restorative and rehabilitation procedures, to the detriment of preventive actions and the promotion of health. Thus, the development of initiatives in the field of education and prevention regarding oral health is essential, emphasizing actions that target paying total, overall attention to the elderly, the social dimension of the illnesses standing out, as well as the role of the State as supplier of health and quality of life for all citizens.

KEY WORDS: elderly. oral health.self-perception.

O objetivo deste trabalho foi analisar as percepções de um grupo de idosos sobre a perda de dentes. Realizouse uma pesquisa qualitativa que utilizou O Discurso do Sujeito Coletivo como técnica metodológica para a ordenação dos dados. A análise das entrevistas e a construção do Discurso do Sujeito Coletivo revelaram informações sobre os pensamentos e valores associados à perda de dentes no grupo. Os principais resultados sugerem que a falta de dentes trouxe problemas funcionais e psicológicos, mas que parecem ser compensados pela resolução do problema estético. As justificativas reveladas pelo sujeito coletivo para o edentulismo refletem predominantemente o modelo de atenção à saúde, em que predominam procedimentos cirúrgicorestauradores e reabilitadores, em detrimento de ações preventivas e educativas. Desta forma, torna-se imprescindível o desenvolvimento de iniciativas no campo da educação e prevenção em saúde bucal, enfatizando ações voltadas para a atenção integral do idoso, destacando-se a dimensão social das doenças e o papel do Estado como provedor da saúde e da qualidade de vida de todos os cidadãos.

PALAVRAS-CHAVE: idoso. saúde bucal. autopercepção.

\footnotetext{
*Elaborado a partir de Santos (2006).

${ }^{1}$ Curso de Odontologia, Universidade Federal de Santa Maria/UFSM, RS. <unfer @terra.com.br >

${ }^{2}$ Curso de Odontologia, UFSM. <katiabraun@smail.ufsm.br>

3,4 Acadêmicos, Curso de Odontologia, UFSM. <carolpafiadache@yahoo.com.br>. <leorampal@yahoo.com.br>
} 


\section{Introdução}

O crescimento do número de idosos na população tem provocado um aumento significativo de estudos que se propõem a investigar os fenômenos que cercam o envelhecimento humano.

$\mathrm{Na}$ área da saúde, este processo tem provocado a discussão sobre a reorganização da atenção proporcionada aos idosos, visando à qualificação do cuidado em saúde nas diversas áreas de conhecimento.

No Brasil, o último levantamento epidemiológico mostra que os brasileiros na faixa etária de 65 a 74 anos já perderam 93\% dos seus dentes (Ministério da Saúde, 2004). Este quadro revela a precariedade da saúde bucal na população idosa brasileira e denuncia a falta de cuidados a que foram submetidos estes indivíduos ao longo de sua vida.

Na Odontologia, a preocupação com os idosos reside no fato, entre outros, de que a capacidade mastigatória está intimamente ligada à condição nutricional e esta, à saúde geral dos indivíduos, o que repercute na sua qualidade de vida. Embora a estética dentária seja importante, a cavidade bucal deve ser vista em sua plenitude, pois por meio dela existe a integração social do indivíduo (Brunetti \& Montenegro, 2002).

$\mathrm{Na}$ área da educação em saúde tem sido dada ênfase à articulação entre os saberes técnico e popular para possibilitar que as comunidades e o próprio indivíduo possam conhecer e controlar os fatores que afetam e determinam sua saúde. $\mathrm{O}$ autodiagnóstico e o autocuidado potencializam o desenvolvimento de ações de saúde junto à população idosa, pois as mutilações dentárias produzem incapacidades que nem sempre são percebidas como problemas funcionais relevantes (Freire Jr. \& Tavares, 2005; Narvai \& Antunes, 2003).

O objetivo deste trabalho foi identificar e analisar as percepções dos indivíduos sobre a perda de dentes, como forma de aumentar o conhecimento e qualificar as ações e os serviços voltados para a terceira idade.

\section{Metodologia}

O método para coleta dos dados partiu de um corte qualitativo. A população integrante foi composta por idosos de sessenta anos ou mais, de ambos os sexos, que participavam de um evento de saúde e lazer para a terceira idade, na Universidade Federal de Santa Maria.

Os dados foram obtidos por meio de entrevista individual semiestruturada com base em duas perguntas que serviram como balizadoras do tema: "O senhor / a senhora já perdeu algum dente?" e "O que significa para o senhor / a senhora ter perdido este (s) dente (s)?". O entrevistado tinha liberdade de falar sobre o tema e de relatar sua história da maneira que lhe fosse conveniente.

Partindo da perspectiva de um estudo qualitativo, a amostragem seguiu critérios inerentes a este tipo de investigação, considerando-se suficiente o número de entrevistas no momento em que foram observados a reiteração e o esgotamento das categorias nos discursos dos sujeitos entrevistados (Bosi \& Mercado, 2004).

As entrevistas, num total de 23 , foram gravadas, e os discursos foram 
transcritos literalmente pelos pesquisadores. Para a análise dos dados, foi adotada a abordagem metodológica proposta por Lefèvre (Lefèvre et al., 2000) - O Discurso do Sujeito Coletivo.

Cada entrevista foi analisada individualmente após sucessivas leituras, coletando-se as expressões-chave e a respectiva idéia central. Em seguida, foram destacadas as categorias temáticas consideradas mais significativas. A síntese dos discursos dos entrevistados representa o discurso do sujeito coletivo para cada categoria temática.

De acordo com os critérios éticos, a adesão dos entrevistados foi voluntária, posterior à leitura e explanação dos objetivos do estudo, e seguida da assinatura do termo de consentimento informado. O projeto de pesquisa $\left(\mathrm{N}^{\circ} 015770\right)$ foi submetido ao Comitê de Ética em Pesquisa do CCS/UFSM, recebendo aprovação.

\title{
Resultados e Discussão
}

A população estudada foi constituída por idosos funcionalmente independentes e participantes ativos de grupos de terceira idade, aposentados, predominantemente do sexo feminino e com idades variando entre 55 e 84 anos. Segundo dados preliminares de um levantamento de saúde bucal, $87 \%$ de idosos possuem algum tipo de prótese dentária (Unfer, 2004).

Os pensamentos e os valores associados à perda de dentes pelos idosos entrevistados foram organizados segundo dois temas principais: as idéias centrais que os compõem e os Discursos do Sujeito Coletivo correspondentes.

\section{Tema 1: Justificativas para a perda de dentes}

\section{Idéia Central 1: falta ou dificuldade de acesso a serviços odontológicos}

\author{
Morando na campanha, há setenta anos, imagina o que era este \\ mundo, essa vida há sessenta anos atrás. Eu morava pra fora, lá \\ na colônia, não era bem instruído, não fazia tratamento. Eu \\ cheguei a botar cinza quente pra aliviar a dor. Tinha os dentes \\ muito estragados. Hoje, tem dente estragado quem quer, pois \\ quando eu era novo, era moço, não havia a facilidade que tem \\ hoje, já tem recursos que substituem os dentes, ou substituem \\ a estética. Naquele tempo, estes recursos eram de última \\ necessidade. O problema é a situação financeira. A gente vai \\ indo, vai indo, vai estragando. No fim, a gente acaba tirando o \\ que resta e coloca uma dentadura. Em parte, foi descuido meu. \\ Um pouquinho de relaxamento. Eu tinha medo de ir ao \\ dentista, sentia a anestesia, sentia a extração e me dava \\ hemorragia. E aí fui relaxando, fui deixando, fui deixando e...
}

Considerando o acesso como qualquer situação que permite e facilite a entrada de um indivíduo a um serviço de saúde, percebe-se que, para os 
idosos, há um conjunto de situações que impedem ou não facilitam a utilização de serviços de saúde bucal. Entre estas estão as dificuldades econômicas, culturais, e sociais. Nem todos os pacientes chegam à terceira idade com condições financeiras de arcar com os custos do tratamento odontológico, principalmente o protético. Aliam-se a esta situação a necessidade de deslocamentos e a ajuda de terceiros (Narvai \& Antunes, 2003; Brunetti \& Montenegro, 2002). Além disso, embora exista déficit de atendimento a idosos, muitos não buscam atendimento nos serviços públicos, pois são desestimulados pela demora e pela qualidade dos serviços prestados (Jitomirski, 2000). Nestes locais, os idosos constituem um grupo de menor prioridade.

\section{Idéia central 2: desconhecimento sobre as causas e o controle das doenças bucais}

Eu tinha 10, 13, 14 anos, não pensava em dentista, não sabia nem o que era dentista, me criei assim, nem escovava os dentes. Minha mãe escovava os dentes com cinza, nem sabia o que era pasta de dente. Minha gengiva inflamava e meus dentes afrouxavam. Às vezes, eu tirava até com a mão. Até hoje não fiquei sabendo o porquê, só sei que afrouxou. Talvez o problema seja daquela piorréia que afrouxa os dentes. Eu tive que arrancar, fui obrigada, foi muito ruim porque eu tinha a dentadura boa, dentes sãos, novos, com toda a idade que eu tinha. Senti muita dor. Um arrebentou aqui em cima, saiu a furo pro lado de fora. Obturei, mas depois já não dava mais pra obturar, então mandei tirar tudo, os que estavam bons e os que estavam ruins.

As manifestações dos idosos neste estudo refletem os resultados dos estudos epidemiológicos na população adulta e idosa, evidenciando a alta prevalência de cárie dentária, doenças periodontais e edentulismo. A prevenção em odontologia teve sua implementação iniciada na década de 1970, mas com ênfase para a população escolar. Até o momento, os cuidados para os idosos não têm sido contemplados devidamente nos programas de saúde bucal.

Para Jitomirski (2000), os serviços de saúde devem e podem incluir a proteção à saúde bucal de idosos entre suas atividades normais. As ações educativas devem ser intensificadas, proporcionando orientações específicas, enfatizando a adoção de comportamentos compatíveis com uma boa saúde e estimulando que os idosos realizem o auto-exame bucal. 0 autodiagnóstico de problemas bucais pode representar a possibilidade de ampliação da cobertura por parte dos sistemas preventivos, de recuperação e de manutenção da saúde.

Shankai (2000) coloca que a incorporação de hábitos e modos de vida saudáveis requer que a população idosa tenha conhecimento deles para querer adotá-los, e queira para pedir e fazer. Assim, é preciso proporcionar a informação e a orientação básica para que as percepções de necessidades 
de saúde sejam reais e se transformem em atitudes pessoais e de reivindicações de medidas governamentais para a proteção da saúde bucal.

\title{
Idéia Central 3: conseqüência do modelo de atenção em saúde bucal
}

\begin{abstract}
Um pouquinho da época. Porque, na minha época, se estragava um dente, em vez de os dentistas obturar, já arrancavam. E aí ... perdia. A gente fica sentida. Talvez por causa de uma dor terrível no nervo trigêmeo. Não tinha nada a ver com o dente e alguns dentistas não queriam retirar o dente. Como eu não melhorava daquele sintoma fui no SESC. Me aconselharam que lá eu conseguiria tirar os dentes, então tirei três dentes.
\end{abstract}

Brunetti \& Montenegro (2002) colocam que, no passado, as intervenções em dentes fraturados ou com mobilidade implicavam exodontia e colocação de prótese parcial, evoluindo até a colocação de uma prótese total. 0 quadro de alta prevalência de edentulismo no Brasil reflete um modelo de atenção cirúrgico-restaurador. Principalmente em serviços públicos, as extrações em massa se constituem na única forma de atendimento oferecido.

Nesse contexto, sem um enfoque conservador e preventivo, as intervenções evoluem de sucessivas restaurações, exodontias, colocação de próteses parciais, até a colocação de próteses totais.

\section{Tema 2: Conseqüências da perda de dentes}

\section{Idéia Central 1: influência na saúde}

\begin{abstract}
Eu gostaria de ter todos os meus dentes, é muito triste, imensamente triste mesmo, perder os dentes, eu perdi muito em termos de saúde. Não há como dente natural, é confortável, acho um tesouro. Dentes naturais significam saúde. Eu tinha meus dentes maravilhosos, uma dentadura linda. Eu tenho só 6 dentes naturais, então, fica aqueles vãos, aquela falha nos dentes, atrapalha. Quando extraio um dente, eu digo: - Vou ficar com um dente a menos. Quem tem os dentes bons tem que cuidar, pois mais tarde fará muita falta. A falta de dente poderá se tornar uma dor de cabeça, qualquer coisa, pra saúde.
\end{abstract}

Se nos reportarmos para a definição de saúde bucal levantada pela I Conferência Nacional de Saúde Bucal, no mesmo ano da VIII Conferência Nacional de Saúde, veremos que ela é parte integrante e inseparável da saúde geral. Para a população idosa, significa condições biológicas e psicológicas adequadas, de modo que os indivíduos exerçam funcionalmente a mastigação, deglutição e fonação, além de exercitarem a auto-estima e o relacionamento social por meio da estética, sem inibição ou constrangimento contribuindo, deste modo, para a saúde geral. Havendo 
dificuldades em alguma dessas funções ou estado, estaremos diante de um quadro de incapacidade, que pode acometer os indivíduos de formas variáveis (Narvai \& Antunes, 2003).

Neste estudo, os idosos parecem reconhecer que a presença dos dentes naturais determina ou colabora para a saúde, embora não esteja claro, para eles, de que forma o desconforto percebido pela perda de dentes pode alterar a saúde.

\title{
Idéia central 2: prejuízo à mastigação
}

\author{
Eu acho que muda muito, muito mesmo. A gente não consegue \\ se alimentar direito, não pode mastigar o alimento direito. Se eu \\ tivesse meus dentes, eu podia comer uma espiga de milho. É \\ impossível até pra comer carne. O pessoal acha graça que eu \\ corto no garfo... tenho que cortar a carne mais pequenininha. Eu \\ não posso pegar uma maçã ou um pão e dar uma dentada \\ daquelas gostosas. Tenho que pegar uma faca e cortar os \\ pedacinhos. Eu gostava muito de comer cana, mas agora não \\ posso mais, a gente não pode comer nada que aperta. A chapa é \\ outra coisa. Não é como os dentes da gente. A gente não tem a \\ força nos dentes pra cortar porque os dentes postiços nunca são \\ firmes na boca. As próteses vão gastando e não cortam muito. É \\ enjoado para mastigar, tem muitas coisas que a gente não pode \\ comer com esses dentes porque resvala. Então, às vezes, como \\ até muito ligeiro. Não tem nada melhor do que mastigar com os \\ dentes naturais.
}

Os idosos percebem que a mastigação não é realizada com naturalidade e conforto, e que há necessidade de selecionar o tipo de alimento ou a forma de consumi-lo, por meio de estratégias que facilitem a ingestão.

A perda de dentes e a diminuição do fluxo salivar em idosos diminuem a capacidade de mastigar e deglutir adequadamente o alimento, comprometendo a saúde geral e o bem-estar do idoso. A mudança de uma dieta saudável para uma dieta com predominância de carboidratos e alimentos menos consistentes pode não conter os nutrientes adequados às necessidades biológicas, causando estados anêmicos e apáticos em pessoas mais suscetíveis. Além disso, este tipo de alimentação pode causar atrofia na musculatura mastigatória, com repercussão na estética facial e na autoestima do idoso (Brunetti \& Montenegro, 2002).

Nem mesmo a substituição dos dentes por próteses confere o conforto e a naturalidade necessários para uma alimentação adequada. Nesse sentido, destaca-se a importância da execução de um tratamento protético biologicamente orientado, adequada às reais necessidades do idoso, proporcionando o conforto e a segurança necessários para a mastigação. Também é preciso orientar os portadores de próteses sobre os controles periódicos que devem ser realizados pelo dentista. A desadaptação das bases é comum devido a reabsor ção óssea, e a perda da altura facial pode ser conseqüência da abrasão dos dentes artificiais. 


\title{
Idéia Central 3: problemas na fonação
}

Tenho problema, dificuldade para falar, conversar. É difícil.

Embora se saiba que as perdas dentárias contribuem para aumentar a dificuldade de fonação, neste estudo, apenas três pessoas relataram sentir dificuldades nesta função, o que foi comprovado também no estudo de Narvai \& Antunes (2003).

\section{Idéia Central 4: problemas psicológicos}

\author{
Eu não acho confortável estar com os dentes que não são meus. \\ A gente não se sente a mesma pessoa. Começando pela higiene. \\ Muitas vezes, a gente tem que sair da mesa e chegar no toalete \\ e escovar dentes e dentadura. Para mim, é difícil, não me sinto \\ bem, fico encabulada de estar escovando a prótese. Isso me \\ constrange muito. Não me interessa se os outros estão ali, não \\ sei se estão me olhando ou não, mas eu sempre espero não ter \\ ninguém no toalete pra eu tirar minha escovinha de dente.
}

Na população estudada, a presença de prótese é uma situação comum. No caso das removíveis, o processo de higiene bucal exige a retirada da prótese para a limpeza adequada. Isto pode gerar constrangimento aos portadores, principalmente quando não há privacidade no local. Conforme relata Wolf (1998) em seu estudo, mesmo em situações extremas, como doenças graves ou realização de cirurgias, "ficar sem as próteses provoca sensações de humilhação, vergonha e sentimentos de desproteção".

\section{Idéia Central 5: implicações estéticas}

Se eu quebrar um dente eu entro em pânico, eu vou procurar um dentista, eu faço qualquer coisa. Eu acho horrível a pessoa sem dente ou desdentada. É uma coisa desagradável. Eu cuido dos meus dentes! As duas dentaduras são postiças. Uma vez quebrei um dente, fiquei louca, desesperada, pois onde encontrar um dentista, era sábado. No outro dia, eu disse pra minha filha: - Eu vou sair, se eu encontrar um dentista que coloque esse dente de volta na chapa, eu volto pra casa, senão, eu não volto, vou fazer qualquer coisa, não volto pra casa desdentada. Porque o principal na pessoa pra mim é o rosto! Já mudei 2 vezes, não, 3 vezes. Uma vez eu mandei fazer uma prótese. Até foi uma prima minha e afilhada. Nossa, ficou horrível, me senti horrível! Uma semana depois, eu mandei fazer outra. Essa aqui já faz uns 6, 8 anos que eu tenho. Não sei... acho que não implica em nada, nenhum problema, ainda mais que são laterais, são bem atrás, não são dentes frontais, nem se nota. 
A preocupação com a reposição dos dentes perdidos é maior quando a estética está envolvida, e menor quando o restabelecimento da função dentária é necessário. No último levantamento das condições de saúde bucal da população brasileira, verificou-se que o uso de próteses superiores superou o de próteses inferiores, e uma das razões pode ser explicada pela questão estética que envolve a perda de dentes anteriores superiores (Ministério da Saúde, 2003).

A auto-imagem está relacionada a um padrão ideal imposto pelas exigências sociais. Assim sendo, a expressão: “o principal na pessoa é o rosto" revela a importância da imagem para os padrões desejáveis pela sociedade (Wolf, 1998).

\title{
Idéia central 6: problemas causados pelas próteses
}

\author{
Dizem que é horrível se acostumar com a prótese inferior, por \\ isso eu estou agüentando. Agora mesmo, mandei fazer esses \\ dentes, mas não estou me acertando com eles, ficou diferente, \\ ficou saliente, machuca. Fiquei meio queixuda, não é aquilo que \\ era. Para o ano, vou ter que fazer outra prótese nova. De vez \\ em quando, cai o pivô, aí eu corro lá no dentista e ele coloca de \\ novo. Incomoda um pouco, a superior não tanto, mas não \\ consigo dormir com a prótese inferior.
}

Conforme foi mencionado, a possibilidade de desajuste das próteses removíveis, por conta da reabsorção óssea ou do desgaste dos dentes artificiais, pode acarretar vários problemas. A adaptação da prótese inferior é sempre mais crítica, pois o índice de reabsorção óssea na arcada inferior é maior que na superior. A falta de acompanhamento e controle da adaptação pode ocasionar o aparecimento de lesões na mucosa bucal e problemas no sistema neuromuscular, aumentando a incidência de nãouso, especialmente as próteses removíveis inferiores (Brunetti \& Montenegro, 2002).

\section{Idéia Central 7: compensação pelo uso de prótese}

\begin{abstract}
Não mudou porque tive que usar dentes postiços, artificiais. Eu tive que colocar pivô. Nem sei se ainda usam. Eu estranhei de fazer prótese, mas agora eu estou acostumada, agora é bom, está como era antes, acostumei rápido, acho que é a mesma coisa. Minha prótese é muito boa porque ela foi bem feita. 0 dentista extraía os dentes e já colocava a prótese. Isso me cansou, me judiou muito, mas agora eu nem sei se eu tenho prótese. Estou muito bem, melhor do que os dentes que eu tinha. Prá mim é dente natural, principalmente a superior, a inferior não. Pelo menos, a gente não fica desdentado.
\end{abstract}

Para muitos idosos, a possibilidade de acesso ao uso de uma prótese parece superar as dificuldades com as extrações dentárias e o comprometimento 
das funções bucais. O uso de dentes artificiais ou de aparelho protético é capaz de melhorar a auto-estima e as relações interpessoais, uma vez atendidas as expectativas do indivíduo (Narvai \& Antunes, 2003; Wolf, 1998).

\section{Considerações finais}

A utilização da metodologia qualitativa para a apreensão das percepções dos idosos sobre os problemas bucais, visualizadas por meio do Discurso do Sujeito Coletivo, permitiu conhecer aspectos relevantes que devem ser considerados nos projetos e programas desenvolvidos para este grupo populacional.

Percebe-se que o sujeito coletivo não parece ter conhecimento das causas das doenças bucais e as formas de prevenir e controlar suas manifestações, antes que seja necessário intervir mediante procedimentos cirúrgicos, restauradores ou reabilitadores.

Ressalta-se a necessidade de conscientizar os idosos sobre a importância de revisões periódicas para a avaliação das próteses em relação aos aspectos de estabilidade e retenção e pela possibilidade de as próteses mal-adaptadas gerarem danos em tecidos moles e duros da cavidade bucal.

Por outro lado, os portadores de próteses mal-adaptadas ou pessoas que não tenham substituído artificialmente seus dentes perdidos podem estar comprometendo sua saúde geral pela perda da eficiência mastigatória, além de colocar em risco, também, a qualidade nutricional da dieta alimentar.

I gualmente, é preciso levar em consideração os fatores psicológicos que envolvem os indivíduos que perderam seus dentes, dando atenção aos danos psíquicos e sociais que envolvem esta situação e que nem sempre são verbalizados claramente aos profissionais de saúde.

Torna-se imprescindível o desenvolvimento de iniciativas no campo da educação e prevenção em saúde bucal, enfatizando comportamentos voltados para auto-exame, controle de lesões cariosas e gengivoperiodontais e manutenção das próteses.

É de fundamental importância, ainda, evidenciar a dimensão social das doenças e o papel do Estado como provedor da saúde, proporcionando qualidade de vida a todos os cidadãos.

\section{Referências}

BOSI, M. L. M.; MERCADO, F. J. (Orgs.) Pesquisa qualitativa de serviços de saúde. Petrópolis: Vozes, 2004.

BRASIL. Ministério da Saúde. Projeto SB Brasil 2003: condições de saúde bucal da população brasileira 2002-2003. Resultados principais. Brasília: Ministério da Saúde, 2004.

BRUNETTI, R.; MONTENEGRO, F. L. B. Odontogeriatria: noções de interesse clínico. São Paulo: Artes Médicas, 2002.

FREIRE JUNIOR, R. C.; TAVARES, M. F. L. A saúde sob o olhar do idoso institucionalizado: conhecendo e valorizando sua opinião. Interface - Comunic., Saúde, Educ., v.9, n.16, p.147-58, $2004 / 2005$.

JITOMIRSKI, F. Atenção a idosos. In: PINTO, V.G. Saúde bucal coletiva. 4.ed. São Paulo: Santos, 
UNFER, B. ET AL.

2000. p.120-35.

LEFÈVRE, F.; LEFÈVRE, A. M. C.; TEIXEIRA, J. J.V. O discurso do sujeito coletivo: uma nova abordagem metodológica em pesquisa qualitativa. Caxias do Sul: EDUCS, 2000.

NARVAI, P. C.; ANTUNES, J. L. F. Saúde bucal: a autopercepção da mutilação e das incapacidades. In: LEBRÃO, M. L, DUARTE, T.A.O. SABE - Saúde, Bem-Estar e Envelhecimento - o projeto Sabe no município de São Paulo: uma abordagem inicial. Brasília: OPAS, 2003. p.120-40.

SHINKAI, R. S. A.; CURY, A. A. D. B. O papel da odontologia na equipe interdisciplinar: contribuindo para a atenção integral do idoso. Cad. Saúde Pública, v.16, n.4, p.1099-109, 2000.

UNFER, B. Avaliação de saúde bucal em idosos participantes de projetos do NIEATI-UFSM. Relatório de projeto de extensão. Santa Maria: Curso de Odontologia, 2004.

WOLF, S. M. R. O significado psicológico da perda dos dentes em sujeitos adultos. Rev. APCD, v.52, n.4, p.307-16, 1998.

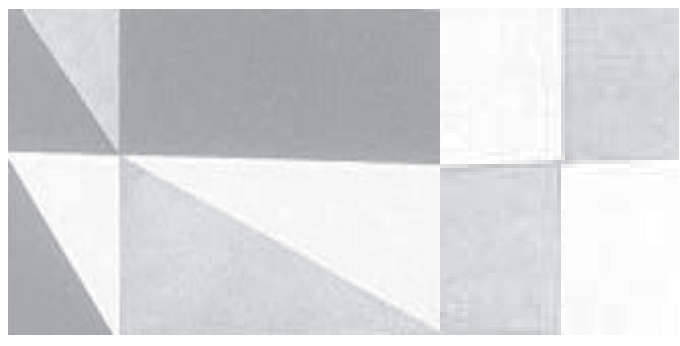

UNFER, B. ET AL. Autopercepción de la pérdida de dientes en ancianos. Interface Comunic., Saúde, Educ., v.10, n.19, p.217-26, jan/jun 2006.

El objetivo de este trabajo fue analizar las opiniones de un grupo de ancianos sobre la pér dida de dientes. Una investigación cualitativa fue realizada con la utilización del discurso del sujeto colectivo como técnica metodológica para el ordenamiento de los datos. El análisis de las entrevistas y la construcción del discurso del sujeto colectivo revelaron informaciones sobre los pensamientos y los valores asociados a la pérdida de dientes en este grupo. Los resultados principales sugieren que la falta de dientes trajo problemas funcionales y psicológicos, pero que parecen ser compensados por la resolución del problema estético. Las justificativas del sujeto colectivo para el edentulismo reflejan predominantemente el modelo de atención a la salud, en que los procedimientos quirúrgico-restauradores y rehabilitadores son privilegiados, en detrimento de acciones preventivas y educativas. De esta forma, el desarrollo de iniciativas en el campo de la educación y la prevención en salud bucal son esenciales, acentuando las acciones dirigidas hacia la atención integral del anciano, destacando la dimensión social de las enfermedades y el papel del Estado como proveedor de la salud y de la calidad de la vida de todos los ciudadanos.

PALABRAS CLAVE: ancianos. salud bucal. autopercepción.

Recebido em: 13/09/05. Aprovado em: 10/02/06 